\title{
Chronic Liver Diseases: From Development to Novel Pharmacological Therapies
}

\author{
Maria Borrello ${ }^{1}$ and Derek Mann ${ }^{1}$ \\ ${ }^{1}$ University of Newcastle upon Tyne
}

November 25, 2021

\begin{abstract}
Chronic liver diseases comprises a broad spectrum of burdensome diseases that still lack effective pharmacological therapies. Our research group focuses on Fibrosis which is a major precursor of liver cirrhosis. Fibrosis consists in a progressive disturbance of liver sinusoidal architecture characterised by connective tissue deposition as a reparative response to tissue injury. Multifactorial events and several types of cells, participate in fibrosis initiation and progression and the process still needs to be completely understood. The development of experimental models of liver fibrosis alongside the identification of critical factors progressing fibrosis to cirrhosis will facilitate the development of more effective therapeutic approaches for such condition. This review provides an overlook of the main process leading to hepatic fibrosis and therapeutic approaches that have emerged from a deep knowledge of the molecular regulation of fibrogenesis in the liver.
\end{abstract}

\section{Hosted file}

Borrello_Mann_BJP_231121.DAM (2).docx available at https://authorea.com/users/448043/ articles/546925-chronic-liver-diseases-from-development-to-novel-pharmacologicaltherapies

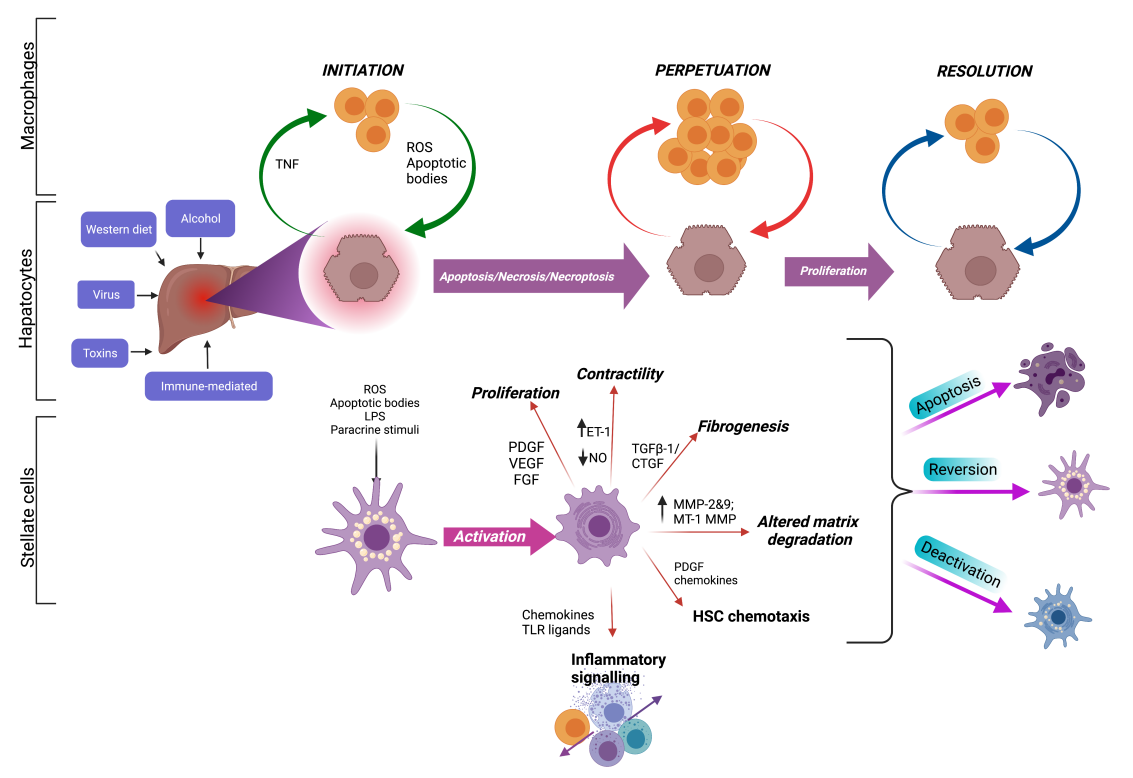




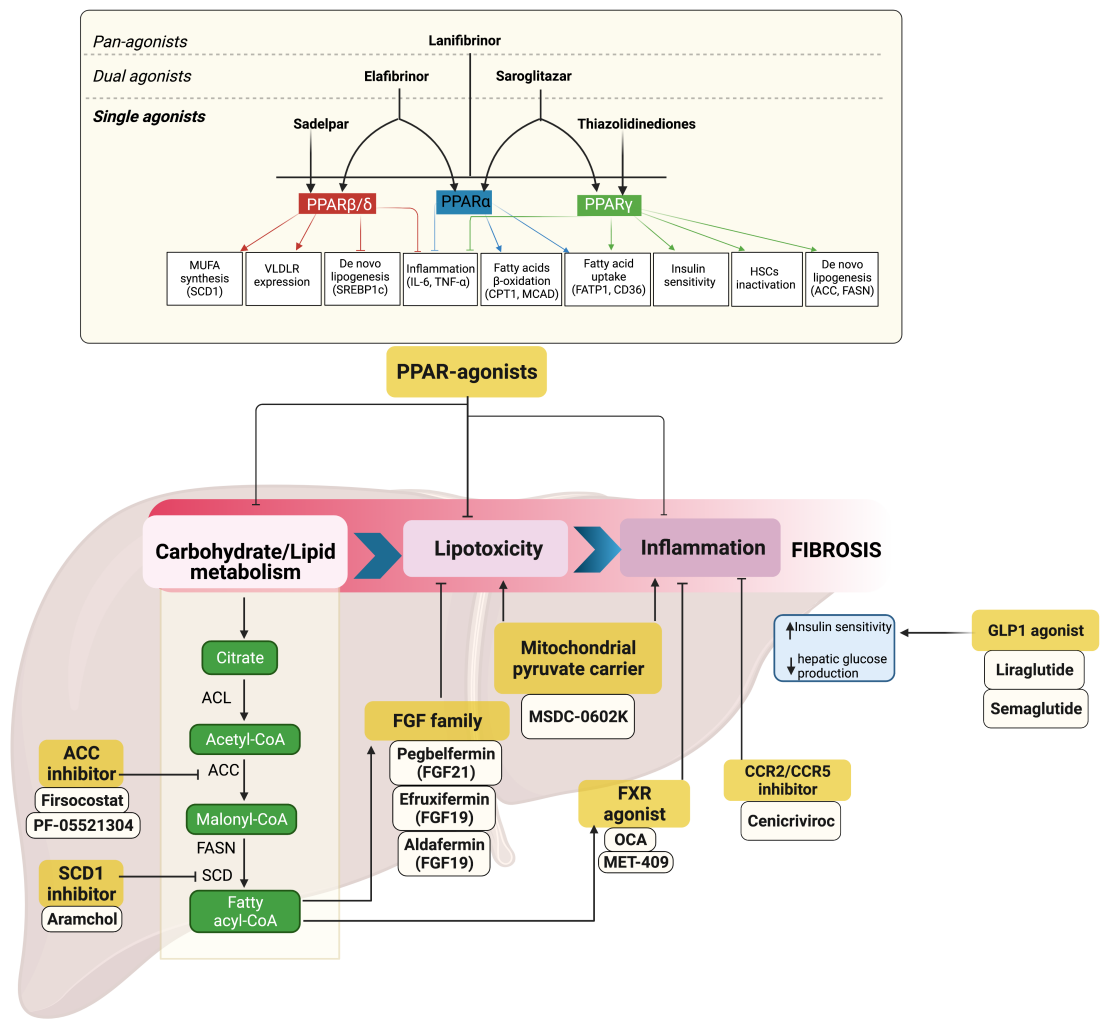

